\title{
New Responsibility as Editor of Sadhana
}

The Council of Indian Academy of Sciences has entrusted me the responsibility of Editor of Sadhana from 1 July 2013. I sincerely thank the Academy for bestowing this honour.

Sadhana was started in 1984 as flagship journal of the Indian Academy of Sciences (earlier published as Proc. Eng. Sci. which was started in 1978). Eminent academics and distinguished engineers have served as Editors and members of the editorial board and nurtured the journal over a period of time. I have also served as Editor of this journal Sadhana from 1990-96. During the last two decades, magnificent new technologies and trends such as mobile internet, wireless communications, cloud technologies, social networks, nanotechnology, additive manufacturing, autonomous vehicles, data analytics, renewable energy, energy storage, shale gas exploration, industrial automation and globalization and several others have revolutionized the engineering sciences and industry like never before and have contributed to significant changes of quality of life.

Sadhana always strived hard to tune itself to serve the needs of contemporary research and technology trends. Last few years, Academy is co-publishing Sadhana with Springer (from 2007). Academy has also introduced online submission facility and online peer review capability. The submissions have increased due to worldwide visibility. Sadhana has received 414 manuscripts in 2012 and this year it has already crossed 450 manuscripts and this increasing trend is going to continue. The downloads of articles for the year 2012 is 32,395. The current impact factor of the journal (for 2012) is 0.304 .

In view of the large number of submissions and on diverse fields of emerging engineering subjects, finding the suitable reviewers and to obtain prompt review reports is a big challenge. On the positive side, there is a new wave encouraging youngsters to think original, write technical articles and publish them. Needless to say, we need to watch out for manuscripts with plagiarism, recycling of data or misconduct including fabrication or falsification of data. We are trying to expand the editorial board with active members to shoulder the burden. We will be inviting survey papers on the latest technologies and theoretical developments in the field of engineering science. We will also be publishing special issues on topics of current interest under the guidance of the editorial board. Open call of papers for the special issues will be issued on the Sadhana website and be publicized through Springer marketing media. Further, we want to invite papers from R \& D laboratories to publish their recent innovations in Sadhana. We hope these measures will give new dimension and outlook and stimulate top tier researchers to publish in Sadhana. We invite Engineering community and the Fellows of the Academy to take active interest to submit good quality papers to the journal and help in the reviewing process to make Sadhana, a leading journal of engineering sciences. Our goal should be to increase the impact factor by 10 times in the coming years.

Effort of this scale requires a strong team work and support from all the stakeholders. I look forward to receiving strong cooperation and support from the authors, reviewers and editorial board members to make Sadhana a top tier journal. 